\title{
Endoscopic submucosal dissection with an additional working channel (ESD+): a novel technique to improve procedure time and safety of ESD
}

\author{
Richard F. Knoop ${ }^{1}$. Edris Wedi ${ }^{1}$. Golo Petzold ${ }^{1}$. Sebastian C. B. Bremer ${ }^{1} \cdot$ Ahmad Amanzada $^{1} \cdot$ Volker Ellenrieder $^{1}$. \\ Albrecht Neesse ${ }^{1}$. Steffen Kunsch ${ }^{1}$
}

Received: 20 February 2020 / Accepted: 10 July 2020 / Published online: 16 July 2020

(c) The Author(s) 2020

\begin{abstract}
Background and aims A new external additional working channel (AWC) was recently introduced by which endoscopic submucosal dissection (ESD) can be converted to a technique termed "ESD+". We aim to systematically evaluate this novel technique in flat gastric lesions and compare it to classical ESD.

Methods The study was prospectively conducted in a pre-clinical ex vivo animal model (EASIE-R simulator) with porcine stomachs. Prior to intervention, we set standardized lesions measuring $3 \mathrm{~cm}$ or $4 \mathrm{~cm}$ in antegrade as well as in retrograde positions.

Results Overall, 64 procedures were performed by an experienced endoscopist. Both techniques were reliable and showed en bloc resection rates of $100 \%$. Overall, ESD+reduced time of procedure compared to $\operatorname{ESD}$ ( $24.5 \mathrm{vs.} 32.5 \mathrm{~min}, p=0.025^{*}$ ). Particularly, ESD+ was significantly faster in retrograde lesions with a median of $22.5 \mathrm{vs.} 34.0 \mathrm{~min}$ in $3 \mathrm{~cm}$ retrograde lesions $(p=0.002 *)$ and 34.5 vs. $41.0 \mathrm{~min}\left(p=0.011^{*}\right)$ in $4 \mathrm{~cm}$ retrograde lesions. There were 0 perforations with both techniques. In ESD+, 1 muscularis damage occurred (3.13\%) compared to 6 muscularis damages with ESD $\left(18.75 \%, p=0.045^{*}\right)$.

Conclusions By its grasp-and-mobilize technique, ESD+allows potentially faster and safer resections of flat gastric lesions compared to conventional ESD in an ex vivo porcine model. The potential advantages of ESD+ in terms of procedure time may be particularly relevant for difficult lesions in retrograde positions.
\end{abstract}

Keywords Endoscopic submucosal dissection (ESD) · ESD+technique (ESD+) · Additional working channel (AWC) . Endoscopic mucosal resection $($ EMR $) \cdot$ EMR $+\cdot$ RESECT $+\cdot$ Animal model $\cdot$ EASIE-R model

\section{Abbreviations}

AWC

EFTR Endoscopic full-thickness resection

EMR Endoscopic mucosal resection

EMR+ Endoscopic mucosal resection using the AWC

ESD Endoscopic submucosal dissection

ESD+ Endoscopic submucosal dissection using the AWC

Electronic supplementary material The online version of this article (https://doi.org/10.1007/s00464-020-07808-w) contains supplementary material, which is available to authorized users.

Steffen Kunsch

Steffen.Kunsch@med.uni-goettingen.de

1 Department of Gastroenterology and Gastrointestinal Oncology, University Medical Center Goettingen, GeorgAugust-University, 37075 Göttingen, Germany
FTRD Full-thickness resection device

HAES Hydroxyethyl starch

IRB Institutional Review Board (Ethikkommission)

R0 No residual tumor

SD Standard deviation

Many precancerous gastrointestinal lesions and early gastric cancers can successfully be treated with endoscopic mucosal resection (EMR), a well-established, safe, and cost-effective interventional endoscopic technique [1,2]. EMR features a relatively low technical complexity, rapid procedure times and a low risk of adverse events [3]. However, EMR shows a decreasing rate of en bloc resections in larger lesions [1, 2]. Specifically, en bloc resection of large sessile or laterally spreading polyps measuring $\geq 2 \mathrm{~cm}$ is hardly possible via conventional EMR where en bloc resection, e.g., for colorectal lesions of this size, can only be achieved in about $30 \%$ of 
cases $[3,4]$. Although EMR can be performed in piecemeal technique, tissue fragments are often difficult to analyze for the pathologist, and patients require frequent follow-up endoscopies due to a higher rate of incomplete resections and ultimate recurrences [5].

Classical EMR can be improved by a new external additional working channel (AWC, Ovesco Endoscopy, Tuebingen, Germany). Recently, the possibility of using the AWC was reported and the technique was termed "EMR+" [6-8]. First reports were also published by our group and others on its application and feasibility in humans [6,9]. We also provided experimental data systematically evaluating the AWC in EMR [7, 8]. The AWC seems to extend the spectrum of EMR beyond the critical size of $2 \mathrm{~cm}$, especially showing promising results concerning the rate of en bloc resections in $3 \mathrm{~cm}$ lesions [8]. However, in $4 \mathrm{~cm}$ lesions, also EMR+ reaches its inherent limits with decreasing en bloc resection rates and a relevant risk of perforations [8].

Therefore, endoscopic submucosal dissection (ESD) should be considered for lesions larger than $3 \mathrm{~cm}$. Initially developed in Japan for the en bloc resection of early gastric cancers, ESD has also become an interventional endoscopic procedure in expert centers of the Western world [10-14]. ESD has also been increasingly employed in colorectal lesions and the esophagus. Particularly, ESD offers a sophisticated and anatomically reliable method for the resection of laterally spreading polyps and flat lesions $\geq 2 \mathrm{~cm}$. Theoretically, ESD enables the endoscopist to achieve en bloc resections regardless of tumor size [13]. However, ESD comes along with a relevant rate of adverse events, particularly a higher rate of perforations [3]. ESD is technically complex with a considerable learning curve even for experienced endoscopists. Furthermore, it demands more resources, time, and costs.

It is worthwhile that ESD is optimized by additional endoscopic devices which need to be developed and clinically implemented. There have already been several approaches of enhancing ESD by counter-traction devices, e.g., with the EndoLifter (Olympus, Tokyo, Japan) [15]. The EndoLifter consists of a transparent hood and a bracket to which a grasping forceps is attached [15]. Following and advancing this principle, conventional ESD can be augmented by the AWC mounted on a standard endoscope facilitating a combination of grasper and ESD knife, ESD coagulation dissector or other additional endoscopic instruments. In analogy to EMR+, the technique is termed "ESD+".

ESD+ with the AWC has not been systematically evaluated in animal models or patients before. Here, we investigate the feasibility of this novel method in a pre-clinical porcine ex vivo animal model for the first time. To this end, we prospectively compare the novel technique ESD+ to conventional ESD in the clinically relevant sizes of $3 \mathrm{~cm}$ and $4 \mathrm{~cm}$ in antegrade as well as in retrograde positions in order to investigate, which lesions are particularly appropriate for the indication of ESD+.

\section{Materials and methods}

The study was a prospectively designed ex vivo trial. Since no humans or living animals were included, it was exempt from IRB. We conducted the experiments at our Laboratory for Experimental Endoscopy in the Department of Gastroenterology and Gastrointestinal Oncology of the University Medical Center Goettingen in Germany.

We used cleaned and frozen porcine stomachs. They were defrosted and placed into the EASIE-R simulator (Erlangen Active Simulator for Interventional Endoscopy, Endosim, LLC, Hudson, MA, USA) prior to the procedure. This model has also been evaluated at our research unit for several endoscopic procedures $[7,8]$. The EASIE-R simulator has become widely established in interventional training and endoscopic research [16, 17].

All interventions (ESD and ESD+) were performed by a well-trained endoscopist with previous experience in ESD technique in humans and in animal models.

\section{Preparation of the porcine stomach}

Prior to intervention, we defined standardized flat lesions, measuring $3 \mathrm{~cm}$ or $4 \mathrm{~cm}$ in the porcine stomach by marking with coagulation dots. The lesions were applied either in antegrade or in retrograde position. After suture closure, the stomach was transferred into the EASIE-R model. Esophagus and stomach were then fixed to the plastic shell of the model $[8,17]$.

\section{ESD and ESD+ procedure}

We conducted ESD and ESD+ with a gastroscope (EG-530D Fujinon, Fujifilm, Japan), the AqaNife $2.0 \mathrm{~mm}$ (Ovesco Endoscopy, Tuebingen, Germany) and, in cases of classical ESD, with an ESD cap (Olympus, Japan). We used Hydroxyethyl starch (HAES) as ESD injection fluid, mixed with methylene blue dye in order to optimize visualization and tissue differentiation. ERBE VIAO 200 (ERBE Elektromedizin, Tuebingen, Germany) was used as electrosurgical unit with EndoCut Q 1/1/1 setting.

$\mathrm{ESD}+$ procedures were performed with the AWC device (Ovesco Endoscopy, Tuebingen, Germany). Figure 1 shows the principle of ESD+ with the help of the AWC. In Fig. 2, the use of the ESD+technique in the ex vivo model is illustrated. 

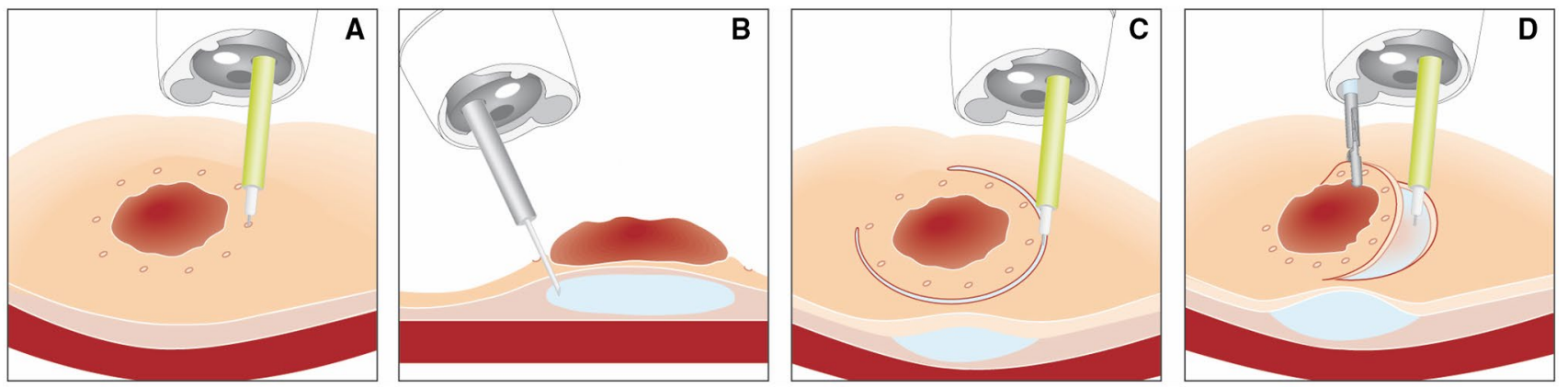

Fig. 1 Principle of ESD+ procedure. A Target lesion, B submucosal injection of the target lesion, C circumferential ESD incision, D mobilization of the lesion's flap with a grasper introduced via the AWC (Source: with permission from Ovesco Endoscopy AG, Tuebingen, Germany)
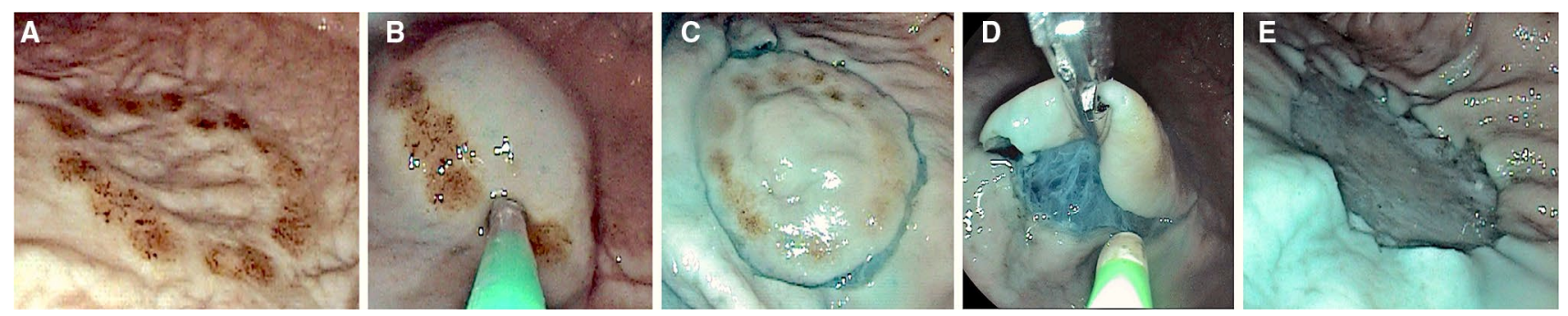

Fig. 2 Application of ESD+in the ex vivo model. A Target lesion, $\mathbf{B}$ submucosal injection of the target lesion, $\mathbf{C}$ circumferential ESD incision, D mobilization of the lesion's flap with a grasper introduced via the AWC, E Post-resection site after ESD+

\section{Additional working channel (AWC)}

The principle of the AWC is shown in Fig. 1. It has a flexible attachment and a shaft with a length of $122 \mathrm{~cm}$ (endoscope insertion length: $103-110 \mathrm{~cm})$. There is an adaptor for fixation at the endoscope handle with Luer-lock, a valve and a sleeve with adhesion tape. The AWC is suitable for the mounting on endoscopes with a diameter from 8.5 to $13.5 \mathrm{~mm}$. The introduction of instruments with an outer diameter of up to $2.8 \mathrm{~mm}$ is possible [8]. We performed all AWC procedures with the AWC in the counterpart position to the working channel.

\section{Data collection}

We recorded the following parameters by an independent observer: Prepared lesion's size $(3 \mathrm{~cm}$ or $4 \mathrm{~cm}$ ), position of the lesion (antegrade or retrograde), time of ESD and $\mathrm{ESD}+$ procedure (minutes), adverse effects (muscularis damage, perforations), rate of en bloc resection ("R0").

Following every ESD and ESD+, the resected specimens were spread out, pinned on cork plates and en bloc resection was evaluated and documented. Procedure time was defined from submucosal injection to complete resection of the lesion. Muscular injury was detected by visual evaluation of every resection site. Potential perforations were evaluated by an insufflation test of the porcine stomach.

\section{Statistical analysis}

We performed data analysis using SPSS (IBM, Armonk, NY, USA). Chi-square-test was used for the analysis of muscularis damage/ perforation events. Mann-Whitney $U$ test was used for the analysis of time of procedure. $P$ values less than 0.05 were considered statistically significant and are marked by $*$.

\section{Results}

In total, 64 endoscopic procedures (32 ESD+, $32 \mathrm{ESD}$ ) were performed by an experienced endoscopist in the ex vivo porcine model (Fig. 3).

In the ESD+ as well as in the ESD groups, lesions with two different sizes were set with a diameter of $3 \mathrm{~cm}(n=16$ per group) and $4 \mathrm{~cm}$ ( $n=16$ per group) (Fig. 3$)$.

In every group, we prepared eight lesions in antegrade and eight lesions in retrograde position (overall 32 antegrade, 32 retrograde lesions) (Fig. 3).

Overall, nine stomachs were used, each with 6-9 lesions, dependent on stomachs' and lesions's sizes. 


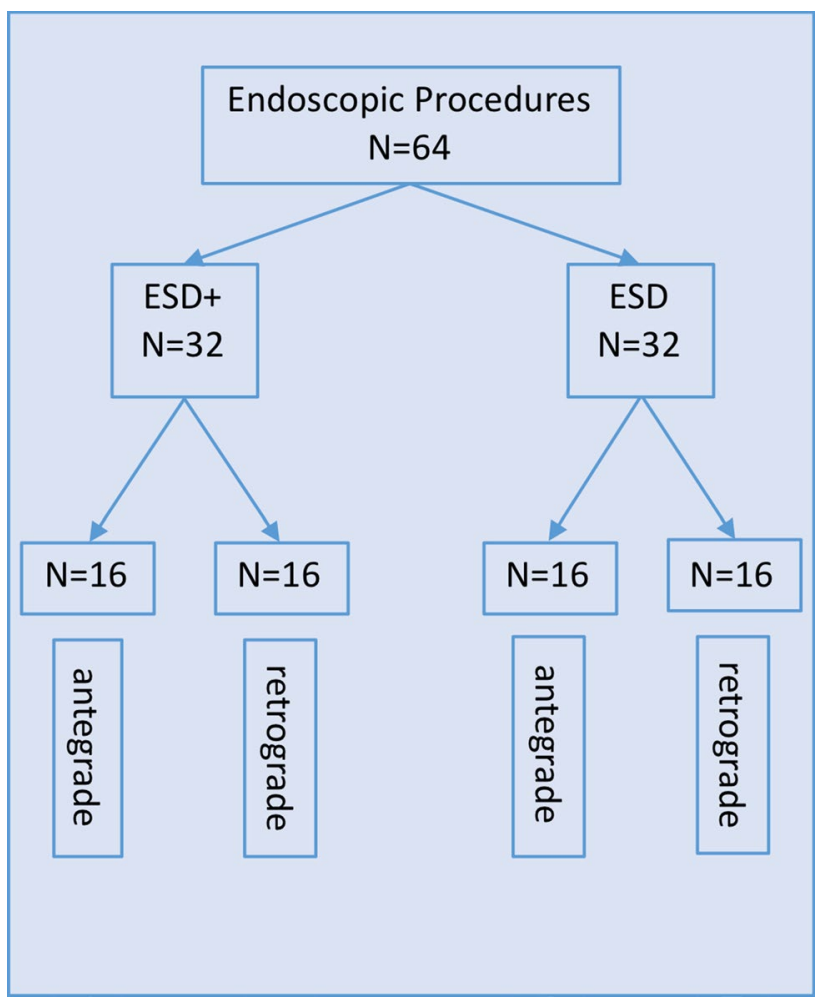

Fig. 3 Study design

\section{Rate of en bloc resection}

ESD+ as well as ESD fulfilled the demands of a secure resection in terms of an en bloc resection rate of both $100 \%$ in all lesions' sizes $(32 / 32 ; 100 \%)$.

\section{Time of procedure dependent on size (minutes)}

In both ESD+ and ESD, overall procedure time was significantly shorter in $3 \mathrm{~cm}$ lesions than in $4 \mathrm{~cm}$ (ESD+21.0 (SD: 4.7) vs. 32.5 (SD: 7.0) minutes, $p=0.01^{*}$; ESD 29.0 (SD: 7.0) vs. 38.0 (SD: 8.8) minutes, $p=0.03 *$ ) (Fig. 4A, B).

\section{Time of procedure dependent on technique (ESD+ vs. ESD, minutes)}

Across all groups, ESD+ was significantly faster than ESD (24.5 $\min$ (SD: 7.8) vs. $32.5 \min \left(\mathrm{SD}: 9.0\right.$ ), $p=0.025^{*}$ ).

In $3 \mathrm{~cm}$ lesions, the time of procedure was significantly shorter with ESD+ compared to ESD (21.0 min (SD: 4.7) vs. $29.0 \mathrm{~min}$ (SD: 7.0), $p=0.006^{*}$ ) (Fig. $4 \mathrm{~A}$ ). Also in $4 \mathrm{~cm}$ lesions, ESD+ was significantly faster than ESD (32.5 min (SD: 7.0) vs. $38.0 \mathrm{~min}$ (SD: 8.8), $p=0.039^{*}$ ) (Fig. 4B).

\section{Time of procedure dependent on the lesion's position (antegrade/ retrograde, minutes)}

In $3 \mathrm{~cm}$ lesions, the median time of procedure with ESD+ in antegrade lesions was $18.5 \mathrm{~min}$ (SD: 4.1) compared to 23.0 min (SD: 5.1) with ESD ( $p=0.223)$ (Fig. 4B). Thus, ESD+ was not significantly faster in antegrade $3 \mathrm{~cm}$ lesions.

In contrast, ESD+ was significantly faster in $3 \mathrm{~cm}$ retrograde lesions with a median of $22.5 \mathrm{~min}$ (SD: 5.0) compared to $\operatorname{ESD}(34.0 \min (\mathrm{SD}: 4.0)(p=0,002 *)$ (Fig. 4A).

In analogy to $3 \mathrm{~cm}$, also in $4 \mathrm{~cm}$ lesions the median time of procedure with ESD+ in antegrade lesions did not significantly differ compared to ESD (30.0 min (SD: 7.4) compared to $31.5 \mathrm{~min}$ (SD: 7.5), $p=0.429$ ) (Fig. 4B).

In retrograde lesions with $4 \mathrm{~cm}, \mathrm{ESD}+$ was again significantly faster with $34.5 \mathrm{~min}$ (SD: 6.1) compared to $41.0 \mathrm{~min}$ (SD: 6.2) with $\operatorname{ESD}\left(p=0,011^{*}\right)$ (Fig. 4B).

\section{Safety and adverse events}

In the ESD groups, 0 perforations and 6 muscularis damages occurred $(6 / 32,18.75 \%)$ with 2 in $3 \mathrm{~cm}$ lesions $(2 / 16$, $12.5 \%)$ and 4 in $4 \mathrm{~cm}$ lesions (4/16, 25.0\%). Of those, one occurred in an antegrade position and 5 occurred in retrograde positions.

Also in the ESD+ groups, there were 0 perforations. One muscularis damage occurred in an antegrade ESD+ lesion of $4 \mathrm{~cm}(1 / 32,3.13 \%)$. In both techniques, the risk of muscularis damages increased with size, showing a total of 2 (2 in ESD and 0 in ESD+) muscularis damages in $3 \mathrm{~cm}$ lesions and 5 ( 4 in ESD and 1 in ESD+) in $4 \mathrm{~cm}$ lesions.

In both techniques, the risk of muscularis damages increased with the difficulty of the lesion's position showing in total 2 (1 in ESD and 1 in ESD+) muscularis damages in antegrade positions and 5 (5 in ESD and 0 in ESD+) muscularis damages in retrograde lesions.

Thus, the rate of muscularis damages was significantly lower under $\mathrm{ESD}+$ compared to $\mathrm{ESD}$ ( 1 vs. $6, p=0.045^{*}$ ).

\section{Discussion}

ESD+ is a combination of ESD with the grasp technique of the recently launched AWC. The aim of our study was to evaluate ESD+ in comparison with classical ESD for the first time.

Over the last decades, endoscopic resection techniques have evolved from EMR to ESD or endoscopic full-thickness resection (EFTR) with the full-thickness resection device (FTRD) in specific indications [18-20]. Many approaches have been tested to accelerate and secure endoscopic resections. For the purpose of achieving better intraluminal tissue traction, various endoscopic devices have been designed, 
Fig. 4 Time of procedure (minutes) dependent on the lesion's position (antegrade/ retrograde). A $3 \mathrm{~cm}$ lesions, B $4 \mathrm{~cm}$ lesions

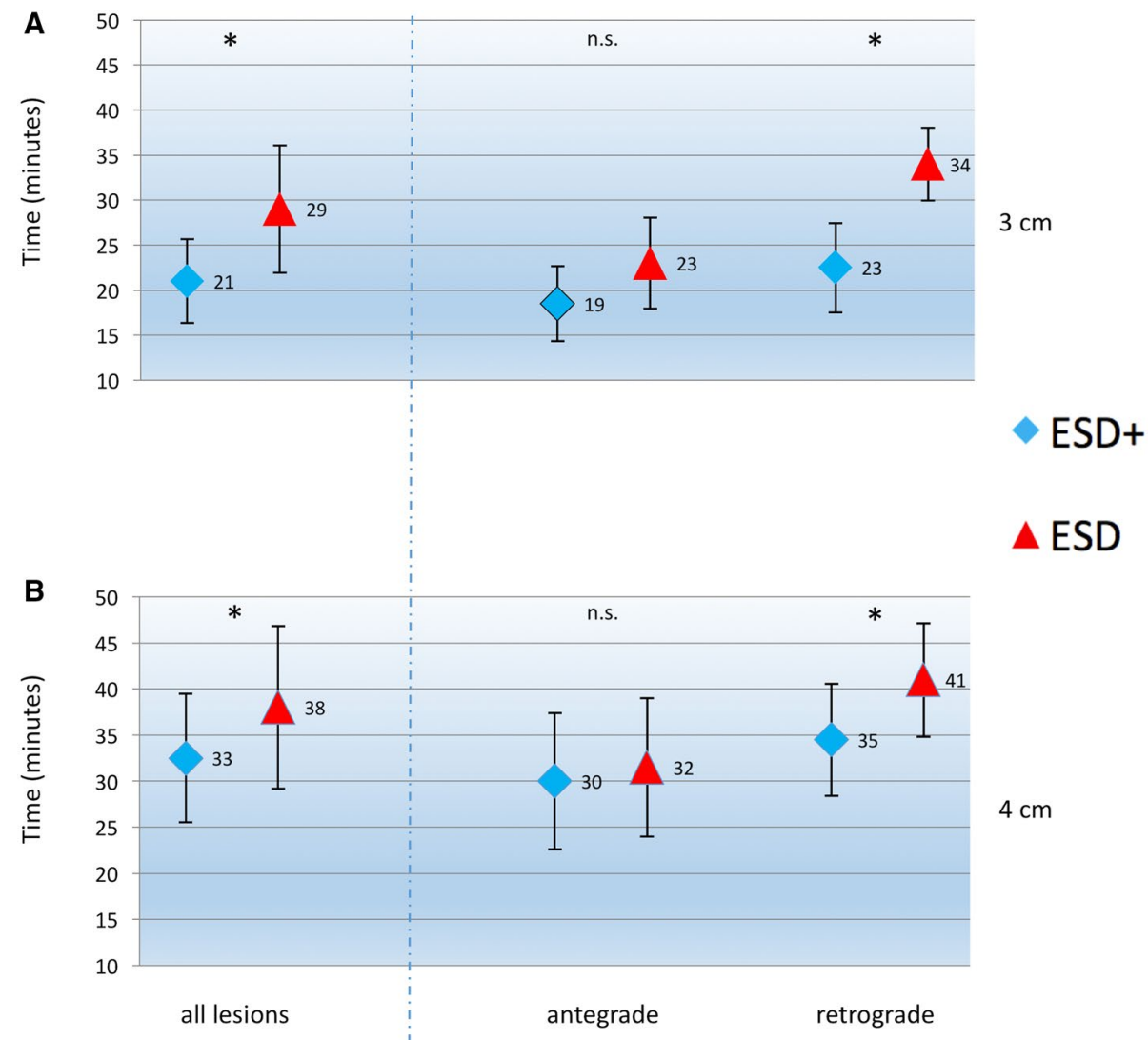

including external forceps, magnetic anchors, clips with attached strings, rubber bands, the EndoLifter, and the creation of a pulley system with clips to facilitate endoscopic traction [15, 21-27]. However, the optimal traction device for endoluminal surgery has not been identified so far. For this reasons, further basic research is necessary in this field.

Today, in the hand of an endoscopic expert, ESD offers a reliable and anatomically convincing method for large resections with lower rates of recurrence and a higher rate of R0 resections compared to EMR [28]. Several meta-analyses compared EMR with ESD in terms of the treatment of early gastric cancer with higher en bloc resection rates, higher histologically complete resection rates and lower recurrence frequencies for ESD [13, 29-31]. However, the advanced technique of ESD has a long procedure time. It is challenging and technically complex with a long flat learning curve also for well-trained experienced endoscopists [13]. Furthermore, ESD is associated with a relevant rate of adverse events, especially perforations in up to 4-10\% [32].

For these reasons, it is desirable to develop and clinically implement additional endoscopic tools in order to accelerate procedure times and to improve the feasibility and safety of ESD especially in challenging anatomic sites, e.g., lesions in retrograde endoscopic positions.
Against this background, ESD+ was recently launched. In analogy to EMR+, it is based on the AWC [7, 9].

In EMR, a grasp and snare technique using a dual channel endoscope has already been described [33-35]. There is also data about the use of double-channel endoscopes in ESD [36, 37]. However, the practicability of a double-channel endoscope in ESD is even more limited than in EMR, especially in retrograde lesions. The close and fixed distance between the two working channels results in a lack of sufficient triangulation, flexibility, and overview. Moreover, a dual channel endoscope is an expensive investment for endoscopy units and is consequently not available in many endoscopy units. The AWC is mounted at the tip of a standard endoscope in analogy to the setup known from the FTRD [18], thus making a dual channel endoscope dispensable. In contrast to a dual channel endoscope, wider and more variable positions of both working channels (standard channel plus AWC) can be achieved by turning its cap [6]. This results in a better visibility and more flexible triangulation of the instruments if required.

The EndoLifter by Olypmus has also been a promising approach. However, the EndoLifter is limited to its grasping forceps fixed on a metal bracket and is only approved for gastric ESD. Compared to the EndoLifter, the AWC used in 
ESD+ is more flexible as it functions as a full-featured additional working channel with the opportunity of introducing various endoscopic instruments which can be independently applied to the intraluminal target.

First of all, our results represent the high reliability of ESD+ and ESD in both lesions' sizes of 3 and $4 \mathrm{~cm}$ in terms of an en bloc resection rate of each $100 \%$. As known from clinical everyday-life, procedure time rises with the lesion's size and the difficulty of its position (e.g., antegrade vs. retrograde). This is recapitulated by our data in both sizes in ESD+ as well as in ESD.

Most importantly, in our setting, ESD+ renders preparation and resections faster. This becomes most evident in the more challenging retrograde lesions. This was significant as well in $3 \mathrm{~cm}$ as in $4 \mathrm{~cm}$.

However, we found that the benefit of ESD+ was somewhat diminished in larger lesions and subsequent resection flaps, most likely due to fact the AWC cannot be simultaneously applied with an ESD cap.

Representing the clinical practice of ESD, our results show that the rate of muscular damages, and consequently potential perforations, principally rises with the size of the lesion. With regard to the technique's safety, we observed significantly fewer muscularis damages of ESD+ compared to ESD. Consequently, ESD+ might enhance the safety of ESD especially in bigger or anatomical challenging lesions.

Our prospective trial was performed in an established and well-evaluated ex vivo animal model. However, there are some limitations concerning the transferability from the porcine ex vivo model to living humans. First, the porcine stomach shows a higher mucosal rigidity compared to the human gastric mucosa that affects the technical opportunities of ESD+ and ESD. Tissue movement, bleeding, histopathological evaluation and other physiological factors can obviously not be recapitulated in our ex vivo model. The resections were conducted by a single endoscopist leading to a good internal validity but coming along with a potential systematic bias. A potential disadvantage of ESD+itself may be tissue damage that can principally occur to the specimen as a result of grabbing the lesion with the forceps via the AWC.

However, until now there is no ESD system commercially available that combines both the AWC and an ESD cap. We think that the development of a specific ESD cap is desirable to enable the simultaneous use of an ESD cap and the AWC in large lesions.

\section{Conclusion}

The newly developed ESD+ technique with an additional working channel (AWC) facilitates faster and safer resections of flat gastric lesions compared to conventional ESD.
In an ex vivo porcine model, we could show that ESD+ works and increases the speed and safety of endoscopic resections. This particularly applies to the resection of lesions in challenging anatomic positions, e.g., in retrograde position.

As already shown in EMR+, the AWC device allows an easy transformation of a standard single-channel endoscope to double-channel functionality. This leads to a good opportunity of bimanual working by triangulation resulting in potentially better intraluminal resections accompanied by a more efficient tissue traction.

In our view, ESD+ could contribute to a safer applicability of ESD particularly in standard endoscopy units with endoscopists less familiar with ESD. However, this ought to be subject of further studies.

Acknowledgements Open Access funding provided by Projekt DEAL. We would like to thank Ovesco AG for providing figures, devices and equipment free of charge. We also thank K. Salzmann and E. Herzog for assisting the experiments.

\section{Compliance with ethical standards}

Disclosure Steffen Kunsch and Edris Wedi conduct hand-on trainings for the Ovesco AG. Ovesco AG provided the AWC device for the study. Richard F. Knoop, Golo Petzold, Sebastian C.B. Bremer, Ahmad Amanzada, Volker Ellenrieder and Albrecht Neesse have no conflicts of interest or financial ties to disclose.

Open Access This article is licensed under a Creative Commons Attribution 4.0 International License, which permits use, sharing, adaptation, distribution and reproduction in any medium or format, as long as you give appropriate credit to the original author(s) and the source, provide a link to the Creative Commons licence, and indicate if changes were made. The images or other third party material in this article are included in the article's Creative Commons licence, unless indicated otherwise in a credit line to the material. If material is not included in the article's Creative Commons licence and your intended use is not permitted by statutory regulation or exceeds the permitted use, you will need to obtain permission directly from the copyright holder. To view a copy of this licence, visit http://creativecommons.org/licenses/by/4.0/.

\section{References}

1. Ferlitsch M, Moss A, Hassan C et al (2017) Colorectal polypectomy and endoscopic mucosal resection (EMR): European Society of Gastrointestinal Endoscopy (ESGE) clinical guideline. Endoscopy 49:270-297

2. Wang J, Zhang XH, Ge J et al (2014) Endoscopic submucosal dissection vs endoscopic mucosal resection for colorectal tumors: a meta-analysis. World J Gastroenterol 20:8282-8287

3. Holmes I, Friedland S (2016) Endoscopic mucosal resection versus endoscopic submucosal dissection for large polyps: a Western Colonoscopist's view. Clin Endosc 49:454-456

4. Zhan T, Hielscher T, Hahn F et al (2016) Risk factors for local recurrence of large, flat colorectal polyps after endoscopic mucosal resection. Digestion 93:311-317 
5. Meier B, Caca K, Fischer A et al (2017) Endoscopic management of colorectal adenomas. Ann Gastroenterol 30:592-597

6. Wedi E, Knoop RF, Jung C et al (2019) Use of an additional working channel for endoscopic mucosal resection (EMR+) of a pedunculated sessile serrated adenoma in the sigmoid colon. Endoscopy. https://doi.org/10.1055/a-0809-4814

7. Wedi E, Knoop R, Jung C et al (2019) EMR + with the AWC improves endoscopic resection speed compared to ESD: a porcine ex-vivo pilot study. Minim Invasive Ther Allied Technol. https:// doi.org/10.1080/13645706.2019.1673778:1-8

8. Knoop RF, Wedi E, Petzold G et al (2020) Endoscopic mucosal resection with an additional working channel (EMR+) in a porcine ex vivo model: a novel technique to improve en bloc resection rate of snare polypectomy. Endosc Int Open 8:E99-E104

9. Walter B, Schmidbaur S, Krieger Y et al (2019) Improved endoscopic resection of large flat lesions and early cancers using an external additional working channel (AWC): a case series. Endosc Int Open 7:E298-E301

10. Gotoda T (2005) A large endoscopic resection by endoscopic submucosal dissection procedure for early gastric cancer. Clin Gastroenterol Hepatol 3:S71-73

11. Repici A, Hassan C, Carlino A et al (2010) Endoscopic submucosal dissection in patients with early esophageal squamous cell carcinoma: results from a prospective Western series. Gastrointest Endosc 71:715-721

12. Odagiri H, Yasunaga H, Matsui $H$ et al (2017) Hospital volume and adverse events following esophageal endoscopic submucosal dissection in Japan. Endoscopy 49:321-326

13. Pimentel-Nunes P, Dinis-Ribeiro M, Ponchon T et al (2015) Endoscopic submucosal dissection: European Society of Gastrointestinal Endoscopy (ESGE) guideline. Endoscopy 47:829-854

14. Ono S, Fujishiro M, Niimi K et al (2009) Long-term outcomes of endoscopic submucosal dissection for superficial esophageal squamous cell neoplasms. Gastrointest Endosc 70:860-866

15. Scholvinck DW, Goto O, Bergman JJ et al (2015) The efficacy of an endoscopic grasp-and-traction device for gastric endoscopic submucosal dissection: an ex vivo comparative study (with video). Clin Endosc 48:221-227

16. Schöfl R, Buchmeier B, Hauder G (2006) Adaptation of the erlangen active simulator for interventional endoscopy (EASIE) model for transmural pancreatic pseudocyst drainage. Endoscopy 38:100

17. Hochberger J, Matthes K, Maiss J et al (2005) Training with the compactEASIE biologic endoscopy simulator significantly improves hemostatic technical skill of gastroenterology fellows: a randomized controlled comparison with clinical endoscopy training alone. Gastrointest Endosc 61:204-215

18. Wedi E, Orlandini B, Gromski M et al (2018) Full-thickness resection device for complex colorectal lesions in high-risk patients as a last-resort endoscopic treatment: initial clinical experience and review of the current literature. Clin Endosc 51:103-108

19. Meining A (2015) Endoscopic full-thickness resection: the logical step toward more extended endoscopic oncologic resections? Endoscopy 47:101-102

20. Hochberger J, Kruse E, Wedi E et al (2011) Training in endoscopic mucosal resection and endoscopic submucosal dissection. In: Cohen J (ed) Successful gastrointestinal endoscopy. WileyBlackwell, Oxford, pp 204-237

21. Kantsevoy SV, Bitner M, Piskun G (2016) New endoscopic platform for endoluminal en bloc tissue resection in the gastrointestinal tract (with videos). Surg Endosc 30:3145-3151

22. Sanchez-Yague A, Kaltenbach T, Yamamoto H et al (2012) The endoscopic cap that can (with videos). Gastrointest Endosc 76(169-178):e161-162
23. Rieder E, Makris KI, Martinec DV et al (2011) The suture-pulley method for endolumenal triangulation in endoscopic submucosal dissection. Endoscopy 43(Suppl 2 UCTN):E319-E320

24. Kondo H, Gotoda T, Ono H et al (2004) Percutaneous tractionassisted EMR by using an insulation-tipped electrosurgical knife for early stage gastric cancer. Gastrointest Endosc 59:284-288

25. Gotoda T, Oda I, Tamakawa K et al (2009) Prospective clinical trial of magnetic-anchor-guided endoscopic submucosal dissection for large early gastric cancer (with videos). Gastrointest Endosc 69:10-15

26. Aihara H, Kumar N, Ryou M et al (2014) Facilitating endoscopic submucosal dissection: the suture-pulley method significantly improves procedure time and minimizes technical difficulty compared with conventional technique: an ex vivo study (with video). Gastrointest Endosc 80:495-502

27. Imaeda H, Hosoe N, Ida Y et al (2009) Novel technique of endoscopic submucosal dissection using an external grasping forceps for superficial gastric neoplasia. Dig Endosc 21:122-127

28. Oka S, Tanaka S, Kaneko I et al (2006) Advantage of endoscopic submucosal dissection compared with EMR for early gastric cancer. Gastrointest Endosc 64:877-883

29. Park YM, Cho E, Kang HY et al (2011) The effectiveness and safety of endoscopic submucosal dissection compared with endoscopic mucosal resection for early gastric cancer: a systematic review and metaanalysis. Surg Endosc 25:2666-2677

30. Lian J, Chen S, Zhang Y et al (2012) A meta-analysis of endoscopic submucosal dissection and EMR for early gastric cancer. Gastrointest Endosc 76:763-770

31. Facciorusso A, Antonino M, Di Maso M et al (2014) Endoscopic submucosal dissection vs endoscopic mucosal resection for early gastric cancer: a meta-analysis. World J Gastrointest Endosc 6:555-563

32. Hochberger J, Köhler P, Kruse E et al (2013) Endoscopic submucosal dissection. Internist (Berl) 54:287-301

33. von Renteln D, Schmidt A, Vassiliou MC et al (2010) Endoscopic mucosal resection using a grasp-and-snare technique. Endoscopy 42:475-480

34. Shetty A, Suarez AL, Dufault DL et al (2016) Endoscopic mucosal resection with grasp-and-snare technique for challenging lesions. Gastrointest Endosc 84:738-739

35. de Melo SW, Cleveland P Jr., Raimondo M et al (2011) Endoscopic mucosal resection with the grasp-and-snare technique through a double-channel endoscope in humans. Gastrointest Endosc 73:349-352

36. Yonezawa J, Kaise M, Sumiyama K et al (2006) A novel doublechannel therapeutic endoscope ("R-scope") facilitates endoscopic submucosal dissection of superficial gastric neoplasms. Endoscopy 38:1011-1015

37. Jung Y, Kato M, Lee J et al (2013) Prospective, randomized comparison of a prototype endoscope with deflecting working channels versus a conventional double-channel endoscope for rectal endoscopic submucosal dissection in an established experimental simulation model (with video). Gastrointest Endosc 78:756-762

Publisher's Note Springer Nature remains neutral with regard to jurisdictional claims in published maps and institutional affiliations. 